\title{
Disease Response Link Group
}

National Cancer Institute

\section{Source}

National Cancer Institute. Disease Response Link Group. NCI Thesaurus. Code C117394.

A sequence of characters used to link multiple disease response records to a single finding. 